\title{
Research and Practice of Teachers' Professional Development in Informatization Process
}

\author{
Xinyang Li \\ School of Foreign Languages, Jilin Agricultural University, Changchun 130118, China
}

Keywords: teachers' professional development; information technology; practice; effect.

\begin{abstract}
The world is in the times of rapid development of information technology currently, so it has brought both opportunities and challenges for the teachers' professional development. In the following, we will discuss the requirements of the informationization process for the teachers' professional development in detail, and propose the support of information technology for teachers' professional practice.
\end{abstract}

\section{Introduction}

At present, our educational ideas and thoughts have gradually changed and made some innovations under the effect of information technology. As the organizers and guides of teaching activities, teachers are more carriers of knowledge and their own ability play a decisive role in the students' development naturally. Therefore, in order to promote the reform steps of basic education and the improvement of educational efficiency and quality, the first is to rely on that informationization environment support and promote the teachers' professional development.

\section{Requirements of Informationization Process for the Teachers' Professional Development}

1. Change the role of teachers. At present, all professions and trades head in the informationization direction as a mainstream trend, education is no exception, in order to allow students to adapt to social development; it is necessary to strengthen the informationization construction of teachers' education, then the role of teachers has taken place change based on that. The teachers' professional development is the object and subject in the informationization education, in addition to the development of their own informationization specialization connotation, students should be helped to optimize the information literacy, it can be seen that teachers' role must be repositioned in the informationization process. The roles of the teacher have multiplicity in the education and teaching, and the specific role depends on the role of the task, or the provider of the learning resource, the counselor, the counselor, replier, the consultant of students, the guide of partner, the guide of the learning method and so on. Teachers should fully understand the huge impact of information process for the traditional teaching methods, and then realize self needs to assume the role in the informationization process, their own teaching ideas and teaching methods are made comprehensive reform and optimization based on that, and promote self to meet new requirements for teachers and their works in the informationization process. The teachers' roles are no longer limited to the simple classroom lecturers or teaching organizers in the informationization process, more contents and requirements are also developed on this basis, teachers should be providers of students' learning materials in the informationization process, meanwhile provide relevant teaching content and resources in accordance with the individual needs of students, answer questions for students in the learning process, help students continually develop new learning methods and learning strategies in the process of learning new knowledge, so the teacher must become partners of students in the learning process.

2. Strengthen technical training in school., the informationization of people is often most easily overlooked In the tendency of informationization construction, the school usually put most of the manpower, material and financial resources into the campus network construction, but rarely integrate the relevant technical for teachers, teaching design, educational ideas and ideological training, and then 
enhancing the teachers' own informationization level become the focus of the industry. Meanwhile under the background of information technology, teachers are required to have skilled application technology and deep theoretical knowledge, so in order to achieve this goal, the school must strengthen the training of teachers, specifically, the technologies need for training include information acquisition technology, communication technology, presentation technology, data processing technology, composition technology, file processing, etc., besides, the teachers are also required to apply the information technology in evaluation communication, teaching, class management and so on. On this account the integration of information technology and subject knowledge is achieved, teachers' knowledge structure adjustment, optimize the teaching acquisition, meanwhile the information technology is used to attract students' attention, carry out independent learning and inquiry and promote the improvement of teaching quality. Information process has brought us plentiful resources and contents, the teacher should study advanced information technology to master how to get these teaching resources from the network world, learn how to select textbooks with targeted teaching effect in a large amount of data, but also study how to comprehensively present the relevant teaching materials for students through study, which requires teachers to do a comprehensive self-learning, of course, schools need to set the relevant training classroom according to the actual condition of school, organize teachers to made concentrated information technology learning after teaching. In this way, through the teacher's independent learning and the organized teaching of school, which greatly improve the teachers' information technology level in the informationization process, and apply it in their own teaching activities, so as to fully present the relevant teaching resources for students, advanced teaching ideas are used to complete the relevant teaching activities, it will undoubtedly help students take advantage in the informationization process, timely grasp the relevant knowledge and information, and ultimately promote the integrated and comprehensive development of students.

3. Improve teachers' information literacy. At present, information literacy is the basic element of teachers' professional development. Therefore, teachers must make full use of modern information technology in modern teaching, so that good information literacy can be taught to students. According to the survey, although most of the teachers are beginning to use the Internet in the actual teaching, but mostly find the course information, send and receive mail, using the Internet to analyze the data, solve the problem or carry out experimental exploration are very few. Thus it can be seen that the applications of information technology of teachers stay in the primary skills and hardware and does expand on the digital learning. Therefore, it is necessary to strengthen the training of teachers, improve their information processing ability and information innovation consciousness, and clearly understand the related function, function and difference of information technology in teaching, and select the special website, image, network course, video, voice and so on for course, which will play the potential advantage of online education, the modern "digital education" teaching method replace the traditional "people' education" teaching method, the computer projection replace textbooks to ensure that teaching effectiveness by doing half the work. The informationization put forward new requirements on the teaching methods and teaching ideas of teachers, so in order to comply with the informationization process, the teacher should take the initiative to improve their information literacy. This is not only the informationization development of the inherent needs smoothly, but also the only way that develops self, improve their professional knowledge and professional skills. The current informationization process propose new requirements the teaching of teachers of various subjects, so teachers need to actively study relevant information technology knowledge for their own teaching subjects, and reasonably use it into the teaching process. For example, multimedia teaching method which is current widely used in all subjects, this method can provide students with various forms of teaching materials such as pictures, music and video, so that can effectively change a single teaching materials in the traditional teaching classroom, thus greatly improve the learning enthusiasm and initiative of students, the rational use of various resources can display the teaching content in a more lively way, so as to improve the students' learning efficiency and learning quality, so that promote students to deepen the understanding and master of knowledge content in the limited classroom time, and apply it to the following learning process. This teaching method is teachers must fully study and 
master in the informationization process, the rational application of advanced teaching methods will help the optimization and development of traditional classroom further, and effectively stimulate students' enthusiasm for classroom learning, and ultimately achieve the purpose of improvement of teaching quality.

\section{The Support of Information Technology for Teachers' Professional Practice}

With the development of multimedia technology, network communication technology and computer technology, people's communication, life, study, thinking and communication way have changed. For the field of education, the development of information technology does not only enrich the means of education, but also reform the educational structure and concept, lift the quality of education to a new height. Here we will specifically introduce the application of information technology in teachers' professional practice.

1. Integration of subject teaching and information technology. The core of combination of the two is essentially to optimize and combine the different elements to achieve maximum education efficiency as the goal. The information technology is applied in the learning and teaching, not only change the teaching behavior, but also provide a lot of information resources, optimize the teaching environment, cultivate the students' information literacy. Through a large number of research, we found that the application of information technology in classroom teaching has been popularized, which also has diversity in the application form, such as students' autonomic or cooperative learning, teaching demonstration. So we can use this as the basis for integration of software environment, establish inquiry teaching mode, and set music editing software, digital media hardware and software equipment for the individual needs of students, etc., provide communication platform for students and teachers, at the same time, provide more information resources with high quality. In order to further enhance the teachers' information security awareness and application concept, develop good habits with information technology, strengthen the teacher's information technology training as well, and establish campus network, forums and blogs and so on, facilitate the exchange of teachers, at the same time, enhance the application concepts, and then implement the concept in practice, so as to explore teaching activities, and promote students' enhancement of learning initiative and enthusiasm.

2. Integration of information technology and teaching evaluation. The teaching evaluation is an important part in teaching activities, the effect is significant, for example, regulate the teaching process, guide the teaching direction, feedback teaching information, find teaching problems and test teaching effectiveness and so on. Affected by individual differences of students, the mastery ability, understanding ability, basic level are all different, if only to take the teacher's static comparison is unfair in the implementation of teaching evaluation. The school uses the information technology to construct the data model of teaching evaluation based on this, it does not only cover the static horizontal evaluation, but also includes the dynamic vertical evaluation, and the teaching situation are shown by the trend, so evaluation effect and objectivity are improved. At the same time, a digital network teaching platform is also introduced, which not only evaluate the learning process and learning objectives, but also record the students' learning situation online real-time, and it as mutual assessment basis for late teachers' evaluation or students' self-assessment. It can be seen that the integration of information technology and teaching evaluation can promote and improve students' learning.

3. Integration of information technology and family-school. Students' growth and success cannot be separated from family education, it can be said that family education and school education occupy the same status; meanwhile the two can also form a complementary relationship. It can be seen that we must build a good communication platform in order to achieve the goal of education, promote teachers and students, students, parents and teachers' exchange and communication, but also achieve democratic management. The specific method can issue each parent to an account, so that it can break space and time to communicate, but also acquire plentiful network resources. Besides, to establish a multi-module communication platform, such as teacher blog, teacher forum, student blog, student 
forum, school message board, anonymous message board, parents message board and teacher message board, so that parents, teachers and students' real thoughts are timely expressed, meanwhile the school and the family play a synergistic role in education, continually improve and optimize school work. Teachers apply information technology to the parents and teachers' communication process, which can effectively improve the efficiency and quality of communication, can help teachers to fully grasp the development state of students' learning, and timely and effectively communicate with the parents of students, accordingly, formulate a teaching method and teaching content that conforms to the development of students' learning and development, and apply it to the actual teaching process. Finally, continually improve the scientific property and target of classroom teaching, and ensure that classroom teaching can fully meet the development needs of students.

4. Integration of information technology and daily office work. The modern information technology is introduced in the daily office work of teachers, not only can improve the efficiency of teaching management, shorten the teacher office practice, meantime rapidly carry out teaching statistics, under the condition that the overall teaching efficiency improve, so that teachers have more time to learn and promote. At present, most of the school office platform is developed by oneself, comprehensively consider the school management framework in the process development, and integrate the e-mail system, task management and school management. With the advance of information technology, mobile terminal platform began to be widely used, and solve the security technology, positioning technology, voice technology and other problems, communication networks, markup language and mobile devices can be used universally, and then led to the development of mobile education, meantime the school will also build the mobile office platform, so that teachers can expand the office work space. It is difficult to achieve a unified multi-campus management by relying on traditional management tools in the school teaching management, but the arrival of the information technology times can achieve campus interconnection, the establishment of the network center will be able to carry out the same management, the input of material and manpower are greatly reduced, provide a unified network application environment and network resources for each teacher, then achieve the resource sharing of campus teachers and students. Moreover, with the increasing popularity of information management, resulting in a large number of management data and management platform, and thus the management efficiency is greatly reduced. Based on this, the integration of various applications can achieve exchange of different platform data. In addition, the information technology is used to integrate resources, achieve single sign-on, that is to ensure when the account security is not logged out, can access the campus network management system, network disk, this method not only improve office efficiency, it has a convenient and quick features as well. It can be said that information technology not only improves the teaching environment, but also provides teachers with a professional practice environment, communication platform between family and school, and it has played a positive role in promoting teacher's self-improvement and professional skills development.

\section{Conclusion}

At present, along with the intensification of social competition, the global economy turn white-hot, which make the cultivation of talents become a widespread concern, and education has become the first issue of people's attention naturally, and in order to better promote the development of the cause of education, there are continued innovation in the education concept and means, so the requirements for teachers' professional development are also getting higher and higher, the teacher is required as the organizer of the teaching process, the decision maker of the teaching strategy, the designer of the teaching, and the analyst of the teaching problem. Modern technology prevails in today; each teacher must become the learner, user and beneficiary of information technology, in this way they can teach, reflect and manage with information technology in practical teaching activities. Besides, the interaction of experts, teachers and students, the network view of good teaching cases and so on can be achieved with the help of information technology platform. It can be said that the teachers' professional 
development get more broad development and expansion space under the role of information technology.

\section{References}

[1]. Ma Ke, Ban Xuan, Yang Zhentao. The practice research of teachers' professional ability development under the informatization environment-inter-school collaboration promotes teachers' professional development [J]. China Educational Technology, 2015 (6): 110-115.

[2]. Yao Xiaoju. The practice research of foreign language teaching informationization based on teacher's professional development [J]. Journal of Kaifeng Institute of Education, 2015, 35 (9): 110-111.

[3]. Zhang Ruijie. The construction practice of network space and promotion strategy research of teachers in primary and secondary school [D]. Central China Normal University, 2015.

[4]. Wang Linyi, Yu Qiao'e. Education informatization and research of teachers' professional development in higher vocational college [J]. Education and Cultivation: Higher Education Forum, 2015 (8): 66-67.

[5]. Zhang Chenwen. Teachers' role and quality orientation research in the informationization process of basic education [J]. Journal of Shandong Agricultural Engineering College, 2015 (8). 